\title{
Association between physical activity and academic performance in Korean adolescent students
}

\author{
Wi-Young So
}

\begin{abstract}
Background: Recently, physical activity (PA) was found to improve cognitive and memory functions in the brain; however, no epidemiological studies have specifically investigated this phenomenon in the Korean adolescent student population. The purpose of this study was to investigate the effects of various types of PA undertaken at various frequencies, on the academic performance of Korean adolescent students.
\end{abstract}

Methods: A total of 75,066 adolescent students $\left(39,612\right.$ males and 35,454 females) from the $7^{\text {th }}$ to the $12^{\text {th }}$ grades took part in the $5^{\text {th }}$ Korea Youth Risk Behavior Web-based Survey (KYRBWS-V) project, conducted in 2009. Using data acquired by that survey, potential relations between PA and academic performance were explored in this current study through multivariate logistic regression analysis incorporating adjustment for covariate variables including age, body mass index, the parents' education level, and the income status of the family.

Results: Compared with boys who did not regularly participate in any vigorous PA, those who did so 2, 3, or 4 times a week had greater odds of reporting an average or above-average academic performance. Compared with boys who did not participate in any moderate PA, those who did so 1, 2, 3, 4, or $\geq 5$ times a week also had greater odds of reporting an average or above-average academic performance. Interestingly, when compared with boys who did not participate in any strengthening exercises, those undertaking strengthening exercises $\geq 5$ times a week had lesser odds of reporting a below-average academic performance. Compared with girls who did not regularly participate in any vigorous PA, those who did so $\geq 5$ times a week had greater odds of reporting an average or above-average academic performance. Compared with girls who did not participate in any moderate PA, those that did so 2 or 3 times a week had greater odds of reporting an average or above-average academic performance. Interestingly, when compared with girls who did not regularly participate in any strengthening exercises, those undertaking strengthening exercises $\geq 5$ times a week had lesser odds of reporting a below-average academic performance.

Conclusions: Our analyses of the relevant data from the KYRBWS-V suggested that vigorous PA was positively correlated with academic performance in the case of boys, and moderate PA was positively correlated with academic performance in both boys and girls. However, strengthening exercises were not positively correlated with academic performance in boys or girls. Furthermore, when undertaken 5 or more times a week, vigorous PA in boys and strengthening exercises in both boys and girls were negatively correlated with academic performance. The results from this study are potentially relevant to the development of future education policies in Korean schools, particularly with regard to early intervention strategies designed to identify and counteract potential factors contributing to academic underachievement.

Correspondence: wowso@swu.ac.k

Department of Human Movement Science, Seoul Women's University, Seoul, South Korea 


\section{Background}

Physical activity (PA) and exercise enhance the functioning of the musculoskeletal and cardiovascular systems $[1,2]$. Additionally, PA is known to confer benefits such as improvement in weight control, bone and muscle strength, mental health and mood, ability to perform daily activities, and life span as well as reduction in the risk of cardiovascular disease, type 2 diabetes, metabolic syndrome, certain cancers, and falls [3]. Furthermore, physical inactivity leads to a sedentary lifestyle that in turn may lead to overweight or obesity [4-6], and is known to have adverse health effects such as increased risk of cardiac disease, musculoskeletal disorders, stroke, type II diabetes, and certain cancers [7]. Therefore, adequate PA is considered important for good health.

Adolescence is an important period for establishing healthy habits [8]. For example, approximately $80 \%$ of obese adolescents grow into obese adults [9]. Many studies have investigated the relation between PA and health effects. The results of these studies suggest that it is important to increase PA and decrease sedentary activities to improve health $[10,11]$. Further, PA was recently found to improve cognitive and memory functions $[12,13]$. These reports showed that regular PA might improve the academic performance of adolescent students. In addition, several studies have reported that PA enhances academic performance and outcomes [14-17]. However, while studies conducted in various regions of the world suggest that PA has beneficial effects on academic performance, and some practical meta-analysis-based evidence associates PA with academic performance [18], there is no epidemiological evidence that indicates whether there is an association between PA and the academic performance of students in Korea. Furthermore, while some regional studies have analyzed this relation in Korean adolescents, no nationwide study has been conducted in this regard. Therefore, this study was conducted to investigate the relation between PA and academic performance in Korean adolescent students.

\section{Methods}

\section{Subjects}

The $5^{\text {th }}$ Korea Youth Risk Behavior Web-based Survey (KYRBWS-V), which was administered in 2009, was a retrospective epidemiological study with a complex sample design that included multistage sampling, stratification, and clustering. This was a national school-based survey conducted by the Korea Centers for Disease Control and Prevention (KCDCP) to estimate the prevalence of health-risk behaviors among adolescent Korean students from the $7^{\text {th }}$ to $12^{\text {th }}$ grade [19]. The KYRBWS-V used a 16-city cluster sample strategy, and the sampling frame of the survey included the entire country. A total of 400 middle and 400 high schools were sampled to evaluate the association between PA and the academic performance of adolescent Korean students, taking into account potential covariate variables. All the details of the data collection procedure have been reported by the KCDCP [19], and this survey has been reported to be valid and reliable [20,21]. The survey was administered to a nationally representative group of Korean adolescent students. Because the survey did not collect identifier information, ethical approval was not required. Further, students were given the option to not participate. The students who chose to participate in the study completed the questionnaire anonymously through the Internet, at their school. Teachers at participating schools were supplied with unique sets of ID numbers printed on tags, and each participating student drew one of these at random before accessing the survey web page and logging in using that unique ID number. A total of 75,066 adolescent students (39,612 boys and 35,454 girls) participated in the study, and the response rate was $97.6 \%$ (out of 76,937 students, 75,066 accessed the questionnaire online). The characteristics of the subjects are shown in Table 1 .

\section{Independent variables}

(1) Frequency of vigorous PA: The examples included digging, soccer, basketball, aerobics, heavy weight lifting, fast cycling, and swimming. The response options were classified into 6 groups: (1) no vigorous PA, (2) once a week, (3) twice a week, (4) thrice a week, (5) 4 times a week, and (6) 5 or more times a week.

(2) Frequency of moderate PA: The examples included cycling at a regular pace, carrying light loads, and playing table tennis, badminton, and doubles tennis. The response options were classified into 6 groups: (1) no moderate PA, (2) once a week, (3) twice a week, (4) thrice a week, (5) 4 times a week, and (6) 5 or more times a week.

(3) Frequency of strengthening exercises: The examples included sit-ups, push-ups, weight lifting, and weight training. The response options were classified into 6 groups: (1) no strengthening exercises, (2) once a week, (3) twice a week, (4) thrice a week, (5) 4 times a week, and (6) 5 or more times a week.

\section{Dependent variables}

Academic performance was evaluated using the following question: In the past 12 months, how has your average academic performance been? The response options were classified into 5 groups: (1) very good performance, (2) good performance, (3) average performance, (4) bad performance, and (5) very bad performance. This variable included only the assessment of the academic performance of students according to examination scores, not taking into account their behavioral conduct, attendance, or other achievements. On the basis of their 
Table 1 The characteristics of the subjects

\begin{tabular}{|c|c|c|c|c|}
\hline \multicolumn{2}{|c|}{ Variables } & Boys $(n=39,612)$ & $\operatorname{Girls}(n=35,454)$ & Total $(n=75,066)$ \\
\hline \multicolumn{2}{|c|}{ Age (years) } & $15.00 \pm 1.73$ & $15.12 \pm 1.77$ & $15.06 \pm 1.75$ \\
\hline \multicolumn{2}{|c|}{ Height (cm) } & $169.58 \pm 8.19$ & $160.08 \pm 5.39$ & $165.09 \pm 8.46$ \\
\hline \multicolumn{2}{|c|}{ Weight (kg) } & $60.14 \pm 11.72$ & $51.47 \pm 7.67$ & $56.04 \pm 10.91$ \\
\hline \multicolumn{2}{|c|}{ Body mass index $\left(\mathrm{kg} / \mathrm{m}^{2}\right)$} & $20.80 \pm 3.21$ & $20.05 \pm 2.58$ & $20.45 \pm 2.95$ \\
\hline \multirow[t]{5}{*}{ Family income status } & Very rich & $2,923(7.4)$ & $1,434(4.0)$ & $4,357(5.8)$ \\
\hline & Rich & $8,985(22.7)$ & $6,908(19.6)$ & $15,893(21.2)$ \\
\hline & Average & $17,743(44.7)$ & $17,706(49.9)$ & $35,449(47.2)$ \\
\hline & Poor & $7,150(18.1)$ & $7,090(20.0)$ & $14,240(19.0)$ \\
\hline & Very poor & $2,811(7.1)$ & $2,316(6.5)$ & $5,127(6.8)$ \\
\hline \multirow[t]{4}{*}{ Father's education level } & Unknown* & 7,297 (18.4) & $5,321(15.0)$ & $12,618(16.8)$ \\
\hline & Middle school or lower & $2,707(6.8)$ & $2,483(7.0)$ & $5,190(6.9)$ \\
\hline & High school & $14,294(36.1)$ & $13,915(39.2)$ & $28,209(37.6)$ \\
\hline & College or higher & $15,314(38.7)$ & $13,735(38.8)$ & $29,049(38.7)$ \\
\hline \multirow[t]{4}{*}{ Mother's education level } & Unknown* & $8,069(20.4)$ & $5,059(14.3)$ & $13,128(17.5)$ \\
\hline & Middle school or lower & $2,447(6.2)$ & $2,490(7.0)$ & 4,937 (6.6) \\
\hline & High school & $17,745(44.7)$ & $18,212(51.4)$ & $35,957(47.9)$ \\
\hline & College or higher & $11,351(28.7)$ & $9,693(27.3)$ & $21,044(28.0)$ \\
\hline \multirow[t]{5}{*}{ Academic performance } & Very good & $04,958(12.5)$ & $03,454(09.7)$ & $08412(11.2)$ \\
\hline & Good & $09,172(23.2)$ & $08,411(23.7)$ & $17583(23.4)$ \\
\hline & Average & $10,544(26.6)$ & $09,675(27.3)$ & $20219(26.9)$ \\
\hline & Bad & $09,661(24.4)$ & $09,477(26.7)$ & $19138(25.5)$ \\
\hline & Very bad & $05,277(13.3)$ & $04,437(12.5)$ & 09714 (12.9) \\
\hline \multirow[t]{6}{*}{ Grade } & $7^{\text {th }}$ & $6,933(17.5)$ & $5,781(16.3)$ & $12,714(16.9)$ \\
\hline & $8^{\text {th }}$ & $6,965(17.6)$ & 5,903 (16.6) & $12,868(17.1)$ \\
\hline & $9^{\text {th }}$ & 7,035 (17.7) & $5,792(16.3)$ & $12,827(17.1)$ \\
\hline & $10^{\text {th }}$ & 6,890 (17.4) & $5,587(15.8)$ & $12,477(16.6)$ \\
\hline & $11^{\text {th }}$ & $6,104(15.4)$ & 6,323 (17.9) & $12,427(16.6)$ \\
\hline & $12^{\text {th }}$ & $5,685(14.4)$ & $6,068(17.1)$ & $11,753(15.7)$ \\
\hline
\end{tabular}

Data are expressed as mean \pm SD or $\mathrm{N}(\%)$.

* These records were omitted from the multivariate logistic regression analysis in Table 2.

responses, the participants were divided into 2 groups: (1) those who reported below-average academic performance and (2) those who reported average or aboveaverage academic performance.

\section{Covariate variables}

Age: The age of the students defined by the KYRBWS-V data was used without any modification.

Body mass index (BMI): The students were asked to report their height and weight, and their BMI $\left(\mathrm{kg} / \mathrm{m}^{2}\right)$ was calculated from the data supplied by each student.

Father's education level: The 4 response options were (1) unknown, (2) middle school or lower, (3) high school, and (4) college or higher. Data from students reporting "Unknown" were omitted from the multivariate logistic regression analysis.
Mother's education level: The 4 response options were (1) unknown, (2) middle school or lower, (3) high school, and (4) college or higher. Data from students reporting "Unknown" were omitted from the multivariate logistic regression analysis.

Family income status: The 5 response options were (1) very rich, (2) rich, (3) average, (4) poor, and (5) very poor.

\section{Data analysis}

All results from this study are shown as mean \pm standard deviation (SD) values. The statistical software SPSS Complex Sample ${ }^{\mathrm{TM}}$ version 18.0 (SPSS, Chicago, IL, USA) was used in all the analyses to evaluate the complex sample survey. For statistical assessments, we took into consideration the complex sampling design of the KYRBWS-V. To 
assess the associations between academic performance and PA, after adjusting for covariate variables such as age, BMI, parents' education level, and family income status, multivariate logistic regression analyses were performed. Statistical significance was set at $p<0.05$.

\section{Results}

Multivariate logistic regression analysis of academic performance in relation to PA patterns, after adjusting for covariate variables including age, BMI, parents' educational level, and family income status, is shown in Table 2.

Compared with boys who did not engage in vigorous PA, the following participants had greater odds of reporting an average or above-average academic performance: those who participated in vigorous $\mathrm{PA}$ twice a week $(\mathrm{OR}=$ 1.198, 95\% CI $=1.080-1.329, p=0.001)$, thrice a week $(\mathrm{OR}=1.287,95 \% \mathrm{CI}=1.156-1.433, p<0.001), 4$ times a week $(\mathrm{OR}=1.265,95 \% \mathrm{CI}=1.117-1.433, p<0.001)$, and 5 or more times a week $(\mathrm{OR}=0.886,95 \% \mathrm{CI}=0.801-0.981$, $p=0.020$ ). Compared with boys who did not engage in moderate PA, the following participants had greater odds of reporting an average or above-average academic performance: those who participated in moderate PA once a week $(\mathrm{OR}=1.121,95 \% \mathrm{CI}=1.021-1.232, p=0.017)$, twice a week $(\mathrm{OR}=1.337,95 \% \mathrm{CI}=1.216-1.471, p<0.001)$, thrice a week $(\mathrm{OR}=1.460,95 \% \mathrm{CI}=1.315-1.621, p<0.001), 4$. times a week $(\mathrm{OR}=1.363,95 \% \mathrm{CI}=1.183-1.570, p<0.001)$, and 5 or more times a week $(\mathrm{OR}=1.135,95 \% \mathrm{CI}=1.013$ $1.271, p=0.029$ ). Compared with boys who did not engage in strengthening exercises, those who participated in strengthening exercises 5 or more times a week had lesser odds of reporting an average or above-average academic performance $(\mathrm{OR}=0.828,95 \% \mathrm{CI}=0.754-0.910, p<0.001)$.

Compared with girls who did not engage in vigorous PA, those who participated in vigorous PA 5 or more times a week had greater odds of reporting an average or above-average academic performance $(\mathrm{OR}=1.532$, 95\% $\mathrm{CI}=1.336-1.757, p<0.001)$. Compared with girls who did not engage in moderate PA, the following participants had greater odds of reporting an average or aboveaverage academic performance: those who participated in moderate PA twice a week $(\mathrm{OR}=1.113,95 \% \mathrm{CI}=$ 1.008-1.229, $p=0.035)$ and thrice a week $(\mathrm{OR}=1.306$, $95 \% \mathrm{CI}=1.161-1.468, p<0.001)$. Compared with girls who did not engage in strengthening exercises, those who participated in strengthening exercises 5 or more times a week had lesser odds of reporting an average or above-average academic performance $(\mathrm{OR}=0.739,95 \%$ $\mathrm{CI}=0.618-0.883, p=0.001)$.

\section{Discussion}

The aim of this study was to investigate the relation between PA and academic performance in adolescent Korean students. The results showed that vigorous PA was positively correlated with academic performance in the case of boys, and moderate PA was positively correlated with academic performance in both boys and girls. However, strengthening exercises were not positively correlated with academic performance in boys or girls. Furthermore, PA and strengthening exercises-when performed 4 times a week or more-were negatively correlated with academic performance in both boys and girls.

Three hypotheses have been proposed to explain the effect of PA or exercise on the brain. First, PA and exercise increase oxygen saturation and angiogenesis in the regions of the brain essential for performing tasks [22,23]. Second, they also increase the activity of neurotransmitters such as serotonin and norepinephrine in the brain, facilitating information processing [24-26]. Third, PA and exercise upregulate neurotrophins such as brain-derived neurotrophic factor, insulin-like growth factor-I, and basic fibroblast growth factor. These neurotrophins support neuronal survival and differentiation in the developing brain [27].

The results of our epidemiological study indicate that PA may increase brain and memory function and that moderate PA has a positive effect on the academic performance of both boys and girls. However, vigorous PA has a positive effect on academic performance only in the case of boys. This difference might be due to the fact that boys undergo rapid physical growth during adolescence [28] and generally prefer sports-related activities such as soccer and basketball, which are defined as vigorous PA according to the KYRBWS-V. In contrast, girls prefer leisure activities that are considered moderate PA [29]. For this reason, we believe that vigorous PA has a positive effect on the academic performance of boys.

Strengthening exercises were not positively correlated with academic performance in the case of boys or girls. PA usually affects the circulatory system [1]. Thus, PA stimulates the brain by increasing blood circulation to the entire body. However, strengthening exercises focus on the musculoskeletal system and not on the circulatory system [2]; therefore, because strengthening exercises stimulate the muscles, they may stimulate brain functions only slightly through increased blood circulation to the entire body. We also found that vigorous PA in boys and strengthening exercises in both boys and girls performed at a frequency of 5 or more times a week negatively affected academic performance. Performing vigorous PA and strengthening exercises 5 or more times a week is time consuming and would potentially deprive students of study time that could be invested in improving their academic performance.

This study has some limitations. First, it was conducted online; therefore, the family income status, parents' educational qualifications, and the students' height and weight were not directly measured; they were 
Table 2 The multivariate logistic regression analysis for school records in relation to the PA patterns

\begin{tabular}{|c|c|c|c|c|c|}
\hline & & Case & OR & $95 \% \mathrm{Cl}$ & $\mathrm{p}$ \\
\hline Boys & & 39,612 & & & \\
\hline \multirow[t]{18}{*}{ Academic performance $\geq$ Average (yes/no) } & No vigorous PA & 7,314 & Reference & & \\
\hline & Once a week & 7,067 & 1.029 & $0.925-1.145$ & 0.602 \\
\hline & Twice a week & 7,847 & 1.198 & $1.080-1.329$ & $0.001^{* *}$ \\
\hline & Thrice a week & 6,994 & 1.287 & $1.156-1.433$ & $<0.001^{* * *}$ \\
\hline & 4 times a week & 3,066 & 1.265 & $1.117-1.433$ & $<0.001^{* * *}$ \\
\hline & 5 times a week or more & 7,324 & 0.886 & $0.801-0.981$ & $0.020^{*}$ \\
\hline & No moderate PA & 7,946 & Reference & & \\
\hline & Once a week & 8,379 & 1.121 & $1.021-1.232$ & $0.017^{*}$ \\
\hline & Twice a week & 8,351 & 1.337 & $1.216-1.471$ & $<0.001^{* * *}$ \\
\hline & Thrice a week & 6,401 & 1.460 & $1.315-1.621$ & $<0.001^{* * *}$ \\
\hline & 4 times a week & 2,539 & 1.363 & $1.183-1.570$ & $<0.001^{* * *}$ \\
\hline & 5 times a week or more & 5,996 & 1.135 & $1.013-1.271$ & $0.029^{*}$ \\
\hline & No strengthening exercises & 13,290 & Reference & & \\
\hline & Once a week & 8,413 & 0.968 & $0.894-1.048$ & 0.423 \\
\hline & Twice a week & 6,354 & 1.076 & $0.978-1.183$ & 0.132 \\
\hline & Thrice a week & 4,804 & 1.021 & $0.920-1.132$ & 0.700 \\
\hline & 4 times a week & 1,966 & 0.910 & $0.785-1.054$ & 0.209 \\
\hline & 5 times a week or more & 4,785 & 0.828 & $0.754-0.910$ & $<0.001^{* * *}$ \\
\hline Girls & & 35,454 & & & \\
\hline \multirow[t]{18}{*}{ Academic performance $\geq$ Average (yes/no) } & No vigorous PA & 15,676 & Reference & & \\
\hline & Once a week & 7,540 & 1.074 & $0.988-1.168$ & 0.094 \\
\hline & Twice a week & 5,628 & 0.958 & $0.869-1.057$ & 0.396 \\
\hline & Thrice a week & 3,661 & 0.943 & $0.832-1.069$ & 0.361 \\
\hline & 4 times a week & 1,009 & 1.073 & $0.879-1.309$ & 0.488 \\
\hline & 5 times a week or more & 1,940 & 1.532 & $1.336-1.757$ & $<0.001^{* * *}$ \\
\hline & No moderate PA & 13,059 & Reference & & \\
\hline & Once a week & 8,640 & 1.034 & $0.947-1.129$ & 0.455 \\
\hline & Twice a week & 6,471 & 1.113 & $1.008-1.229$ & $0.035^{*}$ \\
\hline & Thrice a week & 4,032 & 1.306 & $1.161-1.468$ & $<0.001^{* * *}$ \\
\hline & 4 times a week & 1,164 & 1.065 & $0.893-1.270$ & 0.481 \\
\hline & 5 times a week or more & 2,088 & 0.904 & $0.797-1.024$ & 0.111 \\
\hline & No strengthening exercises & 21,540 & Reference & & \\
\hline & Once a week & 7,045 & 0.995 & $0.922-1.075$ & 0.906 \\
\hline & Twice a week & 3,286 & 0.928 & $0.834-1.034$ & 0.176 \\
\hline & Thrice a week & 1,898 & 0.997 & $0.867-1.147$ & 0.969 \\
\hline & 4 times a week & 564 & 0.764 & $0.579-1.009$ & 0.058 \\
\hline & 5 times a week or more & 1,121 & 0.739 & $0.618-0.883$ & $0.001^{* *}$ \\
\hline
\end{tabular}

OR, Odd Ratio; Cl, Confidence Interval; PA, Physical Activity.

${ }^{*} p<0.05{ }^{* *} p<0.01{ }^{* * *} p<0.001$ tested by multivariate logistic regression analysis (adjusted for age, body mass index, parents' education level, family income status).

recorded by the students themselves. Therefore, these data might be inaccurate. Second, this study did not investigate whether PA might affect attention and alertness at school. Therefore, further studies will be required to determine the extent to which these variables might contribute to attention and alertness in students. Third, the academic performance variable did not incorporate behavioral conduct or attendance at school, and these 
factors might contribute to school performance. Fourth, this study was a retrospective cohort study; thus, we examined only the interrelation between variables, not cause and effect. However, the subject pool was extremely large and highly representative of the wider Korean population (75,066 subjects residing in Korea). Therefore, these results, derived from the KYRBWS-V, can be considered a valid indicator of the relation between PA and academic performance in Korean adolescent students.

\section{Conclusions}

We conclude that vigorous PA undertaken less than 4 times a week was positively correlated with academic performance in the case of boys, and moderate PA was positively correlated with academic performance in both boys and girls, in the adolescent Korean population. However, strengthening exercises were not positively correlated with academic performance in boys or girls. Furthermore, when performed 5 or more times a week, vigorous PA in boys and strengthening exercises in both boys and girls were negatively correlated with academic performance.

Adequate PA can provide health benefits and play a vital role in weight control and reducing the risk of chronic diseases. Furthermore, this study shows that physically active adolescents are more likely to perform better at school. On the basis of the results of this study, we suggest that health-care providers incorporate PA in the students' time tables and encourage them to be physically active and consequently improve academic performance.

\section{Competing interests}

The author has no competing interests.

\section{Acknowledgements}

This work was supported by a special research grant from Seoul Women's University (2012)

\section{Author's contributions}

W-YS contributed to study design and management, performed statistical analyses and drafted the manuscript.

Received: 16 August 2011 Accepted: 2 April 2012

Published: 2 April 2012

\section{References}

1. Leung FP, Yung LM, Laher I, Yao X, Chen ZY, Huang Y: Exercise, vascular wall and cardiovascular diseases: an update (Part 1). Sports Med 2008, 38 (12):1009-1024 [http://www.ncbi.nlm.nih.gov/pubmed/19026018].

2. Di Stasi SL, MacLeod TD, Winters JD, Binder-Macleod SA: Effects of statins on skeletal muscle: a perspective for physical therapists. Phys Ther 2010, 90(10):1530-1542 [http://www.ncbi.nlm.nih.gov/pubmed/20688875].

3. Centers for Disease Control and Prevention: Physical Activity and Health: The Benefits of Physical Activity. Centers for Disease Control and Prevention. 2011 [http://www.cdc.gov/physicalactivity/everyone/health/index.html]

4. Canoy D, Bundred P: Obesity in children. Clinical Evidence(Online) 2011, pii: 0325 [http://www.ncbi.n/m.nih.gov/pubmed/21463538]

5. Park YS, Lee DH, Choi JM, Kang YJ, Kim CH: Trend of obesity in school age children in Seoul over the past 23 years. Korean J Pediatr 2004, 47(3):247257.
6. Thomas AW, Albert JS: Handbook of obesity treatment. 3rd edition. New York: Guilford Press; 2002.

7. World Health Organization: Obesity and Overweight. Global Strategy on Diet, Physical Activity and Health. 2011. [http://www.who.int/mediacentre/ factsheets/fs311/en/]

8. Kvaavik E, Tell GS, Klepp Kl: Predictors and tracking of body mass index from adolescence into adulthood: follow-up of 18 to 20 years in the Oslo Youth Study. Arch Pediatr Adolesc Med 2003, 157(12):1212-1218 [http://www.ncbi.nlm.nih.gov/pubmed/14662578].

9. Daniels SR, Arnett DK, Eckel RH, Gidding SS, Hayman LL, Kumanyika S, Robinson TN, Scott B, Daniels SR, Arnett DK, Eckel RH, Gidding SS, Hayman LL, Kumanyika $S$, Robinson TN, Scott BJ: Overweight in children and adolescents pathophysiology, consequences, prevention, and treatment. Circulation 2005, 111:1999-2012 [http://www.ncbi.nlm.nih.gov/pubmed/15837955].

10. Baker PR, Francis DP, Soares J, Weightman AL, Foster C: Community wide interventions for increasing physical activity. Cochrane Database Syst Rev 2011, 13(4):CD008366 [http://www.ncbi.nlm.nih.gov/pubmed/21491409].

11. Keteyian SJ: Exercise training in congestive heart failure: risks and benefits. Prog Cardiovasc Dis 2011, 53(6):419-428 [http://www.ncbi.nlm.nih. gov/pubmed/21545928].

12. Ploughman M: Exercise is brain food: the effects of physical activity on cognitive function. Dev Neurorehabil 2008, 11(3):236-240 [http://www.ncbi. nlm.nih.gov/pubmed/18781504].

13. Flöel A, Ruscheweyh R, Krüger K, Willemer C, Winter B, Völker K, Lohmann H, Zitzmann M, Mooren F, Breitenstein C, Knecht S: Physical activity and memory functions: are neurotrophins and cerebral gray matter volume the missing link? Neurolmage 2010, 49(3):2756-2763 [http://www.ncbi.nlm nih.gov/pubmed/19853041].

14. Tremblay MS, Inman JW, Willms JD: The relationship between physical activity, self-esteem, and academic achievement in 12-year-old children. Pediatr Exerc Sci 2000, 12:312-323 [http://extranet.nuorisuomi. fi/download/attachments/3245041/the+relationship+between+physical +activity, self-esteem,+and+academic+achievement+in+12-year-old +children.pdf].

15. Welk GJ, Jackson AW, Morrow JR Jr, Haskell WH, Meredith MD, Cooper KH: The association of health-related fitness with indicators of academic performance in Texas schools. Res Q Exerc Sport 2010, 81(3 Suppl):S16-S23 [http://www.ncbi.nlm.nih.gov/pubmed/21049834].

16. Coe DP, Pivarnik JM, Womack CJ, Reeves MJ, Malina RM: Effect of physical education and activity levels on academic achievement in children. Med Sci Sports Exerc 2006, 38(8):1515-1519 [http://www.ncbi.nlm.nih.gov/ pubmed/16888468].

17. Fox CK, Barr-Anderson D, Neumark-Sztainer D, Wall M: Physical activity and sports team participation: associations with academic outcomes in middle school and high school students. J Sch Health 2010, 80(1):31-37 [http://www.ncbi.nlm.nih.gov/pubmed/20051088].

18. Fedewa AL, Ahn S: The effects of physical activity and physical fitness on children's achievement and cognitive outcomes: a meta-analysi. Res $Q$ Exerc Sport 2011, 82(3):521-535 [http://www.ncbi.nlm.nih.gov/pubmed/ 21957711]

19. Korea Centers for Disease Control and Prevention: The Statistics of $5^{\text {th }}$ Kored Youth Risk Behavior Web-based Survey(KYRBWS) in 2009: 2010. 11. 02. [http:// yhs.cdc.go.kr/]

20. Bae J, Joung H, Kim JY, Kwon KN, Kim YT, Park SW: Test-retest reliability of a questionnaire for the Korea Youth Risk Behavior Web-based Survey. $J$ Prev Med Public Health 2010, 43(5):403-410 [http://www.ncbi.nlm.nih.gov/ pubmed/20959711].

21. Bae J, Joung H, Kim JY, Kwon KN, Kim Y, Park SW: Validity of self-reported height, weight, and body mass index of the Korea Youth Risk Behavior Web-based Survey questionnaire. J Prev Med Public Health 2010, 43(5):396402 [http://www.ncbi.nlm.nih.gov/pubmed/20959710].

22. Kramer AF, Hahn S, Cohen NJ, Banich MT, McAuley E, Harrison CR, Chason J, Vakil E, Bardell L, Boileau RA, Colcombe A: Ageing, fitness and neurocognitive function. Nature 1999, 400:418-419 [http://www.ncbi.nlm. nih.gov/pubmed/10440369].

23. Kleim JA, Cooper NR, VandenBerg PM: Exercise induces angiogenesis but does not alter movement representations within rat motor cortex. Brain Res 2002, 934:1-6 [http://www.ncbi.n/m.nih.gov/pubmed/11937064].

24. Kubesch S, Bretschneider V, Freudenman R, Weidenhammer N, Lehmann M, Spitzer M, Gron G: Aerobic endurance exercise improves executive functions in depressed patients. J Clin Psychiatry 2003, 64:1005-1012 [http://www.ncbi.nlm.nih.gov/pubmed/14628975]. 
25. Winter B, Breitenstein C, Mooren FC, Voelker K, Fobker M, Lechtermann A, Krueger K, Fromme A, Korsukewitz C, Floel A, Knecht S: High impact running improves learning. Neurobiol Learn Mem 2007, 87:597-609 [http:// www.ncbi.nlm.nih.gov/pubmed/17185007].

26. McMorris T, Collard K, Corbett J, Dicks M, Swain JP: A test of the catecholamines hypothesis for an acute exercise-cognition interaction. Pharmacol Biochem Behav 2008, 89:106-115 [http://www.ncbi.nlm.nih.gov/ pubmed/18164752].

27. Schinder AF, Poo M: The neurotrophin hypothesis for synaptic plasticity. Trends Neurosci 2000, 23:639-645 [http://www.ncbi.nlm.nih.gov/pubmed/ 11137155].

28. Wilson DK, Williams J, Evans A, Mixon G, Rheaume C: Gender differences in preferences and motivational factors for physical activity in underserved adolescents. J Pediatr Psychol 2005, 30:1-5 [http://www.ncbi.nlm.nih.gov/ pubmed/15784925].

29. Christie D, Viner R: Adolescent development. BMJ 2005, 330(7486):301-304 [http://www.ncbi.nlm.nih.gov/pubmed/15695279].

doi:10.1186/1471-2458-12-258

Cite this article as: So: Association between physical activity and academic performance in Korean adolescent students. BMC Public Health 2012 12:258.

\section{Submit your next manuscript to BioMed Central and take full advantage of:}

- Convenient online submission

- Thorough peer review

- No space constraints or color figure charges

- Immediate publication on acceptance

- Inclusion in PubMed, CAS, Scopus and Google Scholar

- Research which is freely available for redistribution 